\title{
Relationship between egg weight, hatching weight and subsequent body weight in the Japanese quail
}

*Chimezie, V. O., Ademola, A. A., Alli, O. I., Jubril, A. E. and Josiah, B. O. Department of Animal Production,

University of Ilorin Kwara State

Abstract

Corresponding author:*ojo_victoria@yahoo.com.

An experiment to determine the relationship between egg weight, hatch weight and subsequent body weight of the Japanese quail was conducted. A total of 607 eggs collected over 6 days from an existing flock at the Animal Pavilion of the University of Ilorin were used for the experiment. Eggs were individually numbered, weighed and grouped into small (S) medium $(M)$ and large $(L)$ sized eggs based on the mean and standard deviation of the eggs. Mean egg weight were correlated and regressed with mean hatch weight and subsequent weight. Average egg weights were $10.23 \pm 0.84 \mathrm{~g}, 8.49 \pm 0.72 \mathrm{~g}$ and $6.94 \pm 0.93 \mathrm{~g}$ for the large, medium and small group respectively. The result showed relationship between egg weight and hatch weight were positive and highly significant $(P<0.01)$ with values of $0.973,0.977$ and 0.967 for small, medium and large groups, respectively. Relationship between hatch weights and weekly body weights were also positive and significant $(P<0.01)$ for the medium and large groups only but decreased with age. Linear regression equation showed a significant coefficient of determination for weekly body weight using the values for small, medium and large egg weight values. The results of the study showed that egg weight can be reliably used for estimating body weight in Japanese quail and may be used as criteria for early selection of Japanese quail for body weight.

Keywords: Egg weight, hatch weight and body weight.

\section{Introduction}

The influence of egg weight on weight of the hatched chicks and subsequent bodyweight has been reported and are well documented for guinea fowl (Ayorinde et al., 1994), local chicken (Sola-Ojo et al., 2011), and broiler chicken (Abiola etal. 2008) and in the Japanese quail (Ojo et al.,2012) in the sub-Saharan region. Egg weight has been reported to be critical on chick weight (Seker et al., 2004; Khurshid et al., 2004) and on subsequent body weight of the birds (Petek et al., 2003 and Aydin and Bilgehan, 2007). The Japanese quail lay eggs with variable sizes just like its other poultry counterparts. This variation in weight has also led to the variation in weight of chicks hatched and influenced posthatching chick weight (Farooq et al., 2001; Petek et al., 2003; Alkan et al.,2008 and Ojo et al., 2012). Higher average body weight has been reported for larger eggs than in smaller eggs (Petek, 2003 and Ojo et al., 2012). In broiler chicks, Wilson (1991) had also reported a high correlation between egg weight and post hatching chick weight which however decreases with increasing age of the birds, though the greater post hatching weight was said to be more associated with higher feed intake during the period than with greater egg weight. The economic importance of egg weight is thus apparent given its high correlation with subsequent body weight. The smallersized eggs produced by Japanese quails in Nigeria compared with those raised in Europe and Asia (Dudusola, 2010; Ojo et al.,2011) however calls for separate egg grading categories for quail breeder flock in Nigeria.There has been limited information on egg weight and body weights of 
Japanese quail at different growing stages.It is envisaged that this can help in providing information that could assist genetic improvement schemes in the Japanese quail production in Nigeria where the average egg size obtained is quite lower than what is reported in other countries. This study was therefore aimed at determining the relationship existing between egg weight,hatch weight and post hatch body weight of the Japanese quail reared under the Nigerian environmental conditions.

\section{Materials and methods}

The experiment was conducted at the Poultry unit of the Department of Animal Production, Faculty of agriculture, University of Ilorin. All experiments were implemented in accordance with Institutional guidelines on the care and use of animals for scientific studies, and in compliance with generally accepted rules of best practice worldwide.

Origin and management of experimental birds

A total of 607 Japanese quail eggs were collected over a period of seven days from a random-bred population that has been maintained already in the Department for three generations (Ojo et al.,2014). These birds were initially developed at the National Veterinary Research Institute (NVRI) station, Vom (Jos, Nigeria) from fertile eggs obtained from the Republic of Benin in 1992.The collected eggs were numbered and weighed singly using an electronic scale with the sensitivity of $0.01 \mathrm{~g}$. The average weight and standard deviation of the eggs were determined and the eggs grouped into large $(\geq 9.40 \mathrm{~g})$ medium (7.6-9.4g) and small $(\leq 7.6 \mathrm{~g})$ weight group and incubated. The large group consist eggs having weight greater than one standard deviation above the average weight, while all eggs with weight lesser than one standard deviation below the average weight were tagged as small eggs. Eggs having weight that fall between the large and the small were tagged as medium eggs. Day-old chicks were tagged on their wings and kept in brooding pen. Feed and water were supplied ad-libitum throughout the six (6) weeks period of the experiment. Standard prophylactic procedures were also followed.

\section{Data collection}

After incubation, the newly hatched chicks were tagged and weighed according to the group they belong.

Hatched chicks were reared in three separate electrically heated pens and weighed weekly thereafter. Birds were fed diet containing $24 \%$ crude protein and 2700 Kcal Metabolizable energy as recommended by Musa et al. (2008) in Nigeria.

\section{Statistical analysis}

Correlation and simple linear regression analysis were used to determine the relationship between egg weight and chick body weight at different ages. Also the relationship between hatch weight and subsequent body weight was also determined. Statistical analysis was performed using the SPSS (SPSS, 2008). The following linear regression equation was used to predict body weight from various egg sizes.

$Y=a+b x$

Where $Y=$ body weight or dependent variable, $a=$ constant in the regression equation, $b=$ regression coefficient and, $x=$ various egg sizes.

\section{Results and discussion}

Table 1 shows the effect of egg weight on weekly body weight of Japanese quails. Initial chick weights were affected by hatching egg weight with superiority of chicks from the large sized eggs compared to those from small and medium sized eggs. Small eggs produced smaller chicks (4.78g) 
and had smaller body weight at 42 days of age $(127.0 \mathrm{~g})$ compared to medium $(141.08 \mathrm{~g})$ and large sized eggs (146.03g). Birds from large sized eggs were about $19 \mathrm{~g}$ bigger than birds from the small sized eggs. This supports the findings of Farooq et al. (2001) and Petek et al. (2003) that egg weight, chick weight and chick growth are interrelated. The superiority of chicks from the large sized eggs over those from the small sized eggs however decreased from $33.5 \%$ at hatching to $13.03 \%$ at six weeks of age while those from medium sized eggs were inferior by $17.69 \%$ at hatch and only $3.39 \%$ at six weeks of age. Thus it appears there is a compensatory growth with age as the effect of initial disadvantage was overcome.

Table 1: Effect of egg weight group on weekly body weight of Japanese quails

\begin{tabular}{cccc}
\hline AGE (weeks) & SMALL $(\mathbf{g})$ & MEDIUM $(\mathbf{g})$ & LARGE $(\mathbf{g})$ \\
\hline Egg weight & $6.93 \pm 0.43$ & $8.46 \pm 0.72$ & $10.35 \pm 0.84$ \\
0 & $4.78 \pm 0.29^{\mathrm{a}}$ & $5.91 \pm 0.56^{\mathrm{b}}$ & $7.18 \pm 0.70^{\mathrm{c}}$ \\
1 & $15.48 \pm 2.96$ & $16.62 \pm 2.82$ & $18.09 \pm 2.66$ \\
2 & $37.03 \pm 8.03$ & $38.58 \pm 4.94$ & $45.20 \pm 54.02$ \\
3 & $66.19 \pm 11.57$ & $68.65 \pm 7.10$ & $68.87 \pm 6.46$ \\
4 & $90.60 \pm 14.89$ & $97.36 \pm 9.53$ & $100.25 \pm 7.74$ \\
5 & $114.58 \pm 16.87$ & $127.14 \pm 12.29$ & $127.48 \pm 10.35$ \\
6 & $127.00 \pm 19.44$ & $141.08 \pm 15.15$ & $146.03 \pm 18.29$ \\
\hline
\end{tabular}

The result of the correlation coefficient between egg weight group and weekly body weight is shown on Table 2. The correlation between egg weight and hatch weight were highly positive and significant $(\mathrm{P}<0.01)$ with values of $0.97,0.98$ and 0.97 for the small, medium and high egg weight respectively. There was however a decline in the magnitude of correlations between egg weight and chick body weight with advancement in age of birds and by the $6^{\text {th }}$ week of age, the correlation was too low to be significant in the small and the large egg weight group. This supports the findings of Wilson (1991) on a high and positive correlation between egg weight and hatch weight with a decline in the magnitude of correlation as the animal advances in age.

Table 2: Correlation coefficient (r) between egg weight and weekly body weight of Japanese quails

\begin{tabular}{cccc}
\hline AGE (week) & SMALL & MEDIUM & LARGE \\
\hline 0 & $0.97^{* *}$ & $0.98^{* *}$ & $0.97^{* *}$ \\
1 & $0.97^{* *}$ & $0.91^{* *}$ & $0.91^{* *}$ \\
2 & $0.29 \mathrm{NS}$ & $0.78^{* *}$ & $0.71^{* *}$ \\
3 & $0.77^{* *}$ & $0.61^{* *}$ & $0.63^{* *}$ \\
4 & $0.66^{* *}$ & $0.52^{* *}$ & $0.53^{* *}$ \\
5 & $0.61^{* *}$ & $0.43^{* *}$ & $0.34^{*}$ \\
6 & $0.43 \mathrm{NS}$ & $0.34^{* *}$ & $0.25 \mathrm{NS}$ \\
\hline
\end{tabular}

**ignificant level at $(p<0.01) *$ significant level at $(p<0.05) ;$ NS- Not Significant

Table 3 shows the result of correlations between hatch weight and subsequent body weight. High and positively significant $(\mathrm{P}<$ $0.01)$ correlations exist between the hatch weight and subsequent body weight till sixth week of age for the medium and large egg weight groups. However, for the small egg weight group, the degree of relationship between day old weight and subsequent weight was significant up to the $4^{\text {th }}$ weeks only. 
Relationship between egg weight, hatching weight and subsequent body weight

Table 3: Correlation coefficient (r) between hatch weight and weekly body weight of Japanese quails

\begin{tabular}{clcc}
\hline AGE(week) & SMALL & MEDIUM & LARGE \\
\hline 1 & $0.969^{* *}$ & $0.951^{* *}$ & $0.912^{* *}$ \\
2 & $0.325 \mathrm{NS}$ & $0.761^{* *}$ & $0.732^{* *}$ \\
3 & $0.702^{* *}$ & $0.644^{* *}$ & $0.606^{* *}$ \\
4 & $0.585^{*}$ & $0.554^{* *}$ & $0.458^{* *}$ \\
5 & $0.468 \mathrm{NS}$ & $0.400^{* *}$ & $0.350^{*}$ \\
6 & $0.272 \mathrm{NS}$ & $0.283^{* *}$ & $0.296^{*}$ \\
\hline
\end{tabular}

**significant level at $(P<0.01){ }^{*}$ significant level at $(P<0.05)$

Table 4 shows the linear regression equation between egg weight and post hatch body weight. Linear regression equation showed a significant coefficient of determination for weekly body weight using the values for Small, Medium and Large egg weight values. Though the reliability of the coefficient of determination reduced with increase in age of the birds, the values obtained were significant $(\mathrm{P}<0.05)$ till the fifth week of age in all the egg sizes: thus showing the possibility of predicting early body weight from egg weight in the
Japanese quail. The result shows that egg weight can be effectively used in predicting body weight up to adult age in the Japanese quail. This supports the findings of previous authors (Abiola et al., 2008; Ipinyomi et al., 2009; Sola-Ojo et al., 2011). The results of the authors however showed considerable variation in the actual time the association becomes too low to be significant. Some authors (Ayorinde et al., 1994; Sola-Ojo et al., 2011) had earlier reported the reliability of predicting bodyweight from egg size only up to $4^{\text {th }}$ week in the guinea fowl and the Fulani ecotype chicken.

Table 4: Regression equation for estimating weekly body weight (Y) from large, medium and small egg weight $(\mathrm{X})$ of Japanese quail

\begin{tabular}{lllllll}
\hline $\begin{array}{l}\text { Age } \\
\text { (week) }\end{array}$ & $\mathbf{Y}=\mathbf{a}+\mathbf{b X}$ (Large) & $\mathbf{R}^{2}$ & $\begin{array}{l}\mathbf{Y}=\mathbf{a}+\mathbf{b X} \\
\text { (Medium) }\end{array}$ & $\mathbf{R}^{2}$ & $\mathbf{Y}=\mathbf{a}+\mathbf{b X}$ (Small) & $\mathbf{R}^{2}$ \\
\hline 0 & $\mathrm{Y}=-1.12+0.80 \mathrm{X}$ & $0.936^{* *}$ & $\mathrm{Y}=-0.51+0.76 \mathrm{X}$ & $0.954^{* *}$ & $\mathrm{Y}=0.10+0.67 \mathrm{X}$ & $0.947^{* *}$ \\
1 & $\mathrm{Y}=-11.53+2.86 \mathrm{X}$ & $0.823^{* *}$ & $\mathrm{Y}=-13.49+3.56 \mathrm{X}$ & $0.824^{* *}$ & $\mathrm{Y}=-30.92+6.69 \mathrm{X}$ & $0.947^{* *}$ \\
2 & $\mathrm{Y}=-5.03+4.01 \mathrm{X}$ & $0.435^{* *}$ & $\mathrm{Y}=-6.04+5.28 \mathrm{X}$ & $0.588^{* *}$ & $\mathrm{Y}=-0.73+5.45 \mathrm{X}$ & $0.086 \mathrm{NS}$ \\
3 & $\mathrm{Y}=18.67+4.85 \mathrm{X}$ & $0.400^{* *}$ & $\mathrm{Y}=18.03+5.99 \mathrm{X}$ & $0.366^{* *}$ & $\mathrm{Y}=-77.56+20.73 \mathrm{X}$ & $0.597^{* *}$ \\
4 & $\mathrm{Y}=50.26+4.83 \mathrm{X}$ & $0.276^{* *}$ & $\mathrm{Y}=39.87+6.86 \mathrm{X}$ & $0.267^{* *}$ & $\mathrm{Y}=-67.91+22.86 \mathrm{X}$ & $0.439^{* *}$ \\
5 & $\mathrm{Y}=84.19+4.18 \mathrm{X}$ & $0.116^{* *}$ & $\mathrm{Y}=65.44+7.30 \mathrm{X}$ & $0.181^{* *}$ & $\mathrm{Y}=-50.48+23.81 \mathrm{X}$ & $0.371^{* *}$ \\
6 & $\mathrm{Y}=90.38+5.38 \mathrm{X}$ & $0.061 \mathrm{NS}$ & $\mathrm{Y}=79.39+7.29 \mathrm{X}$ & $0.114^{* *}$ & $\mathrm{Y}=-0.78+19.44 \mathrm{X}$ & $0.186 \mathrm{NS}$ \\
\hline **significant level at $(P<0.05)$, NS - Not significant & & &
\end{tabular}

\section{Conclusion}

The results of the study showed that egg weight is positively correlated with hatch weight and subsequent body weight in the Japanese quail. It is also clear that egg weight can be reliably used for estimating body weight up to adult age (6weeks) in the Japanese quail and may be used as criteria for early selection of Japanese quail for improvement of their body weight.

\section{References}

Abiola, S. S., Meshioye, O. O., Oyerinde, B. O. and Bamgbose, M. A. 2008. Effect of Egg Size on Hatchability of Broiler Chicks. Archivos de Zootecnia, 57 (217): 83- 86.

Alkan, S., Karabag, K., Galic, A. and 
Balciogu, M. S. 2008. Effects of Genotype and Egg Weight on Hatchability Traits and Hatching Weight in Japanese Quail. South African Journal of Animal Science. 38 (3) 231-237.

Aydin I, and Bilgehan Y. D. 2007. The Relationship Between Growth Traits and Egg Weight in Pheasants (P. colchicus) Journal of Biology and Environmental Science. 1(3), 117-120.

Ayorinde, K. L., Atteh, J. O. and Joseph, J. K. 1994. Pre- and Post hatch growth of Nigerian Indigenous guinea fowl as influenced by egg Size and Hatch weight. Nigerian Journal of Animal Production, (21): 59-65.

Dudusola, I. O. 2010. "Comparative evaluation of internal and external qualities of eggs from quail and guinea fowl." International Research Journal of Plant Science, 1:112-115.

Farooq M., Aneela K., Durrani F., Mugarrab A. K., Chand, N. and Khurshid, A. 2001. Egg and shell weight, hatching and production performance of Japanese broiler quail. Sarhad Journal of Agriculture, 17: 289-293.

Ipinyomi, I. I., Ayorinde, K. L., Ayantoye, O. I. and Ayigun, A. E. 2010. Relationship among Egg Size and Early Development of Local Chicks. $35^{\text {th }}$ Annual Conference, Nigerian Society of Animal Production.

Khurshid, A., Farooq, M., Durrani, F. R., Sarbiland, K. and Manzoor, A. 2001. Hatching Performance of Japanese quails. Livestock Research for Rural Development, 16(1): 24-28.

Musa U., Haruna E. S. and Lombin L. H.
2008. Quail Production in the Tropics. National Veterinary Institute Press, Vom, Nigeria.

Ojo, V., Ayorinde, K. L. and Fatoki, H. O. 2011. Relationship between Bodyweight and some Egg Production Traits in the Japanese quail (Cortunix cortunix japonica) Nigerian Society for Experimental Biology Journal, 11(2): 89-94.

Ojo, V. Ayorinde, K. L., Fayeye, T. R. and Josiah, B. O. 2012. Effect of Egg weight on Hatchability and Growth Performance of the Japanese Quail in Nigeria. Nigerian Journal of Genetic, 26: 180- 185.

Petek M., Baspinar H. and Ogan M. 2003. Effects of egg weight and length of storage period on hatchability and subsequent growth performance of quail. South African. Journal of Animal Science, 4: 242-247.

Seker, I., Kul, S. and Bayraktar, M. 2004. Effects of parental age and hatching egg weight of Japanese quails on hatchability and chick weight. International Journal of Poultry Science, 3 (4): 159-265.

Sola-Ojo, F. E., Toye, A. A., Ayorinde, K. L., and Afolayan, O. F. 2011. Relationship Between Egg Weight and Subsequent Body Weight in Fulani Ecotype Chicken. Global Journal of Agricultural Science, 10 (2):103-109.

SPSS 17.0. 2008. SPSS 17.0 Command Syntax Reference 2008, SPSS Inc., Ch i c a g . ht t p: // w w w 01.ibm.com/software/analytics/sps S/?prod id=SPSS

Wilson, H. R., 1991. Interrelationships of egg size, chick size, post-hatching growth and hatchability. $W o r l d$ Poultry Science Journal, 47: 5-20.

Received: $14^{\text {th }}$ October, 2019 Accepted: $19^{\text {th }}$ January, 2020 